\title{
Soil Moisture Content and Density Prediction Using Laboratory Resistivity Experiment
}

\author{
Mohd Hazreek Zainal Abidin, Rosli Saad, Fauziah Ahmad, Devapriya Chitral Wijeyesekera, and \\ Ahmad Shukri Yahya
}

\begin{abstract}
Natural soils are an intimate mixture of solid, liquid and gas phases. This study establishes a correlation for moisture content and density of a soil with its electrical resistivity. In the past, most of the conventional geotechnical site investigation required bulky and heavy equipment to determine the geotechnical parameters necessary for design and construction purposes. Consequentially, time and cost of the project is increased especially when dealing with some difficult site such as on mountainous terrain. This study is based on laboratory soil box resistivity meter observations made on soils mixed with additions of consistent increments of 1-5\% of water to 1500 gram of remolded soils in loose condition. At least 24 repetitive resistivity test observations were made and the moisture content and soil density was determined concurrently for each of the tests. The observations showed that the electrical resistivity variation decreased in a curvilinear manner with increasing percentage of moisture content. A regression equation and coefficient of determination, $\mathrm{R} 2$ for moisture content against soil electrical resistivity value was established by moisture content, $w=152.87 \rho-0.312(\rho=$ soil electrical resistivity) and $\mathrm{R} 2=0.7718$ respectively. While a regression equation and $\mathrm{R} 2$ value for bulk density versus soil electrical resistivity value was observed to be $\rho$ bulk $=\mathbf{- 0 . 1 0 7} \ln (\rho)+$ 1.7249 and 0.7016 respectively. Hence, a viable method is demonstrated where the electrical resistivity value was applicable and has a great potential for geotechnical data prediction of parameters such as moisture content and soil density.
\end{abstract}

Index Terms-Correlation, moisture content, soil electrical resistivity and soil density.

\section{INTRODUCTION}

Geotechnical site investigation faces a challenge from time to time especially when working on sites with difficult accessibility in order to gain the parameter for design and construction purposes. Geotechnical parameters are most important in design and construction for most of the natural or manmade civil engineering structure such as slopes, building, foundation, etc. Conventional and important basic soil properties were moisture content, density, specific gravity, cohesion, friction angle, etc. For some construction on sites with difficult access, the problem faced was always with the difficulty of machinery mobilization and operation. This problem solicits alternative techniques to solve or

Manuscript received March 9, 2013; revised June 30, 2013. This work was supported in part by the Universiti Tun Hussein Onn Malaysia, Malaysia and Universiti Sains Malaysia, MALAYSIA

The authors are with the Universiti Sains Malaysia, 11800 Penang Malaysia, on leave from Universiti Tun Hussein Onn Malaysia, Malaysia (e-mail: hazreek@uthm.edu.my,: rosli@usm.my, cefauziah@eng.usm.my, devapriya@uthm.edu.my, shukri@eng.usm.my). minimise the current problem with the adoption of geophysical methods. According to [1], geophysical method has a good prospect in order to solve some of the problems related to the conventional site investigation methods.

Geophysical method was originally championed by people from physical sciences and is now gaining increased popularity with geotechnical and structural engineers. The basis of geophysics is the study of earth using a quantitative physical scence approach. In Malaysia, most ongoing geophysical methods are effectively used for field exploration purposes relating to the engineering, environmental and archeological studies such as subsurface profile mapping in order to locate bedrock [2], boulder and cavity [3], groundwater resources [4] - [7] and contamination [8], [9], leachate migration [10], mining [11] and archeology [12]. Geophysical techniques are an indirect or surface method which consists of seismic, geoelectrical and induced polarization, ground penetrating radar, gravity, magnet and electromagnetic. In Malaysian case studies, resistivity and seismic method was the most practical geophysical method used due to the successful contrast outcome, easily mobilized and time saving. According to [13], most of the popular geophysical methods applied in engineering were seismic and resistivity technique. Traditionally, results of those geophysical methods was based on and used for anomaly contrast and verified with the other direct exploration methods such as drilling outcome (borehole) etc. Since such potential of geophysics in engineering is yet to be realized and developed, the application of these techniques are still not being fully utilized. Problems may arise during the applications when the geophysical methods are not being fully explored by the civil engineers due to their lack of exposure and expertise in this field. According to [1], some of the reasons are due to poor planning of geophysical survey by engineers who lack experience in the techniques, and over optimistic geophysicists leading to inappropriate application of the available techniques.

In geotechnical engineering perspectives, sense of concern and appreciation was commonly viewed from the prospective of contribution and significance due to the geomaterial properties determination and its reliability. The application of alternative methods such as geophysical techniques can be increasingly meaningful in contributing more than its well-known anomaly based outcome since the main task and responsibility of engineers was to design and construct a structure safely. In a developing country like Malaysia, the statistical correlation of geophysical and geotechnical method in soil properties prediction is still an ongoing research with several limitation such as lack of interest, 
confidence, expertise and exposure. The necessity to gain more data with this approach is considered important since it can develop a new technique and database used for properties guidelines prediction which will be applicable in construction industry. According to [14] and [15], resistivity value was highly influenced by pore fluid and grain matrix of geomaterials. Furthermore as stated by [14], electrical current may propagate in geomaterials via the process of electrolysis where the current was carried by ions at a comparatively slow rate. Hence, this study proposed a geotechnical properties prediction (soil moisture content and density) using the statistical correlation of soil resistivity laboratory test and geotechnical laboratory test. This technique has a potential to supply and compliment conventional geotechnical data acquisition due to the efficiency in cost, time and environmental sustainability.

\section{MATERIAL AND METHODS}

11 tests were conducted using laboratory based geophysical and geotechnical experiments. Disturbed soil sample was taken from Universiti Sains Malaysia, Engineering campus site. Soil classification tests such as particle size distribution test based on [16] was carried out. Electrical soil box resistivity test was performed using Nilsson model 400 soil resistance meters by mixing an original mass of $1500 \mathrm{~g}$ of oven dried soil with $1-5 \%$ of distilled water and tested repeatedly at least 24 times (each test used 15, 30, 45, 60 and $75 \mathrm{ml}$ of distilled water based on percentage of water used for $1500 \mathrm{~g}$ of soil). For example, a $15 \mathrm{ml}$ of distilled water was added consistently and mixed thoroughly into the originally loose oven dried soil and continuously tested with each increment of distilled water added using soil box resistivity meter for at least 24 determinations of resistivity. After that, the same procedure was repeated using a 30, 45, 60 and $75 \mathrm{ml}$ of distilled water. Soil box resistivity meter consisted of a 4 pin arrangement consisting of 2 current pin (both being located at the end of the soil box) and 2 potential pin (these being located along the middle of the soil box). The function of two end current pins were to inject direct current (DC current) into the soil while the other two potential pins were used to measure a potential difference for calculating the soil resistivity value. Soil moisture content and density was taken immediately after the soil resistivity was measured. Moisture content test was determined for two samples from each soil box test for final averaging purposes. All results obtained from the experiments were analyzed using a statistical regression method. As referred to in [16], the following equations $1-3$ were used to calculate the resistivity value, bulk density and moisture content.

$$
\rho=R A / L
$$

where $A$ is the cross-sectional area of the sample, $L$ is the length of the sample between the electrodes and $R$ is the mean resistance of the soil sample $(R=V / I)$

$$
\rho_{b u l k}=m / V
$$

where $\mathrm{m}$ is the mass of the soil specimen (solids + water) and $\mathrm{V}$ is the volume of the test specimen (total volume)

$$
w=\left(\left(m_{2}-m_{3}\right) /\left(m_{3}-m_{1}\right)\right) \times 100
$$

where $m_{1}$ is the mass of container, $m_{2}$ is the mass of container and wet soil and $m_{3}$ is the mass of container and dry soil

\section{RESULTS AND DISCUSSION}

A result from wet and dry sieve test showed that the soil was classified as a Clayey SILT. The statistical correlation results from geophysical and geotechnical laboratory test are presented in Fig. 1 and 2. Detailed results from all the percentage of water (1-5\%) used was given in Table I.

Moisture Content vs Resistivity

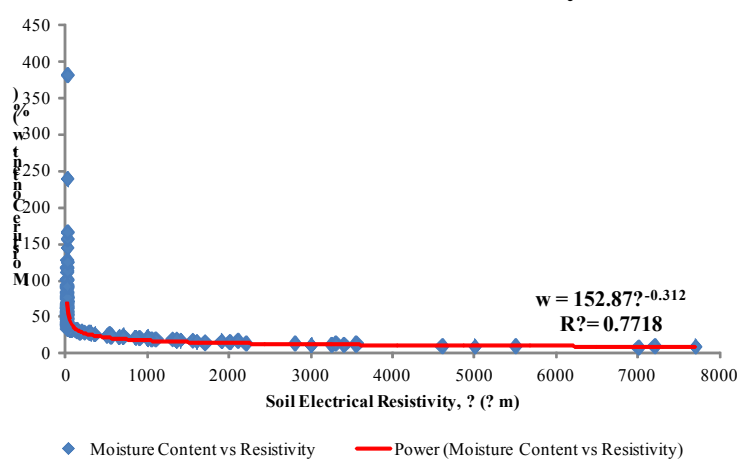

Fig. 1. Moisture content and soil electrical resistivity correlation.

Bulk Density vs Resistivity

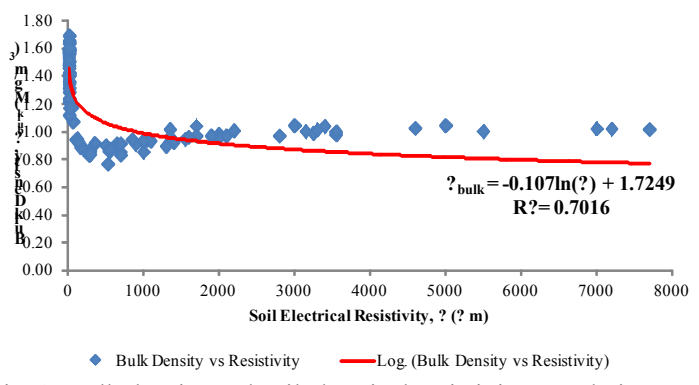

Fig. 2. Bulk density and soil electrical resistivity correlation.

It was found that both correlations showed a curvilinear trend in line with previous researcher findings [17] - [21]. According to Fig. 1 and 2, moisture content and bulk density value was higher with the decrease in soil electrical resistivity value due to the presence of more water content in soil tested. This finding confirmed the past findings which indicated the moisture content value will increase with the decreasing of soil resistivity value [17]-[21]. When water was added continuously from dry soil until it reach oversaturated condition, the ease of current propagation in soil will be increased, thus producing a high to low resistivity value. As reported by [20], ions in pore fluid finds hard to propagate in the low moisture content soil thus producing a low soil conductivity which will cause an increasing of resistivity value.

This study used $1-5 \%$ of water $(15,30,45,60$ and $75 \mathrm{ml})$ since it will allow the reading for some limit and variations. For example, the $1 \& 2 \%$ of water will give more variations for the large resistivity value while $3-5 \%$ of water will increased the variation of low resistivity value. Hence, it was 
found that the range of 1-5\% of water was good enough to produce a soil electrical resistivity correlation with moisture content and soil density from low to high variation.

At the beginning of test, it was found that all the soil tested cannot give any reading due to the limitation of soil sample condition (100\% dry soil conditions which cause the difficulty of current propagation in soil). All soil tested will start give readings after passing some limit of percentage of water added. For this soil box resistivity meter, it was found that the reading will start to exist at $8 \%$ and above of the water added. This phenomenon can also be related to the field resistivity survey where dry condition always gave erroneous observations.

This study found that the resistivity value will continuously decrease as water was continuously added. Despite an overall continuous decrease in resistivity value, a small inconsistency of value reduction from high to low was also recorded. This inconsistency resistivity value was caused by small inconsistent quantity of soil tested for each percentage of water added due to the difficulty of soil handling from dry-moist-saturated-oversaturated. The experiment was carefully performed by filling the soil (mixed thoroughly with water) inside the box without being compacted with the lowest possible void left. However, the workability of soil inside the box was difficult especially when it was at moist to saturated state where the soil was in a highly cohesive condition. The problems continued when it reached saturated to oversaturated state where the quantity of soil tested can be varies due to the large quantity of water added.

Apart from the influence of water, this controlled laboratory study also revealed that the soil electrical resistivity value was highly influenced by the presence of air void content. For example during the moist to nearly saturated condition, the soil tested consisted of some inconsistent voids which increased the soil electrical resistivity value. Furthermore at moist state to nearly saturated state, volume of void was inconsistently present and filled by air which increased the soil electrical resistivity value. According to [3], air filled void posses a higher resistivity value compared with the water filled void.

This study was established to prediction some of the geotechnical parameter such as moisture content and density using controlled laboratory environment. Hence, the prediction is still exposed for some limitation to match the actual field value due to the environmental condition that prevail in the field scale is having higher uncertainties parameter influence compared to the controlled laboratory scale. Based on [20], detailed study related to the field condition such as porosity, degree of saturation, salt concentration in pore fluid, grain size, size gradation, temperature and activity can produce more accurate correlation performed from the laboratory experiment.

\section{CONCLUSION}

The laboratory experiment of soil box resistivity test was successfully being performed. The soil electrical resistivity was greatly influenced by the presence of water and porosity. The correlation of soil electrical resistivity to moisture content and density was presented. The integration of laboratory geophysical and geotechnical method can provide a meaningful contribution for the geotechnical engineers instead of their previous established geophysical field application.

\section{APPENDIX}

All the results from laboratory experiment are given in Table I-V.

TABLE I: SOIL ELECTRICAL RESISTIVITY VALUE, MOISTURE CONTENT AND BULK DENSITY DATA FOR $1 \%$ (15 ML) OF WATER

\begin{tabular}{ccc}
\hline \hline MC $(\%)$ & $\begin{array}{c}\mathrm{P}_{\text {bulk }} \\
\left(\mathrm{Mg} / \mathrm{m}^{3}\right)\end{array}$ & $\rho(\Omega \mathrm{m})$ \\
\hline 7.76 & 1.02 & 7000 \\
8.50 & 1.04 & 5000 \\
9.59 & 1.02 & 4600 \\
10.28 & 1.04 & 3000 \\
11.39 & 0.99 & 3250 \\
12.56 & 1.04 & 1700 \\
13.05 & 1.00 & 2200 \\
14.10 & 0.98 & 2000 \\
14.87 & 0.97 & 1700 \\
15.98 & 1.01 & 1350 \\
17.38 & 0.92 & 1400 \\
18.07 & 0.93 & 1050 \\
18.90 & 0.93 & 1100 \\
20.16 & 0.91 & 900 \\
21.33 & 0.91 & 650 \\
22.44 & 0.86 & 550 \\
23.32 & 0.90 & 500 \\
25.17 & 0.91 & 355 \\
26.96 & 0.87 & 300 \\
27.70 & 0.87 & 225 \\
29.61 & 0.94 & 130 \\
31.52 & 1.07 & 70 \\
32.62 & 1.19 & 48 \\
32.76 & 1.42 & 24 \\
34.55 & 1.42 & 19 \\
\hline \hline
\end{tabular}

TABLE II: SOIL ELECTRICAL RESISTIVITY VALUE, MOISTURE CONTENT AND BULK DENSITY DATA FOR $2 \%(30 \mathrm{ML})$ OF WATER

\begin{tabular}{ccc}
\hline \hline MC $(\%)$ & $\begin{array}{c}\mathrm{P}_{\text {bulk }} \\
\left(\mathrm{Mg} / \mathrm{m}^{3}\right)\end{array}$ & $\rho(\Omega \mathrm{m})$ \\
\hline 9.77 & 1.00 & 5500 \\
11.42 & 0.98 & 3550 \\
13.45 & 0.97 & 2800 \\
15.25 & 0.95 & 2000 \\
17.18 & 0.94 & 1550 \\
18.91 & 0.89 & 1300 \\
21.32 & 0.85 & 1000 \\
23.38 & 0.85 & 700 \\
25.65 & 0.76 & 530 \\
27.68 & 0.83 & 280 \\
29.95 & 0.89 & 190 \\
32.07 & 1.16 & 47 \\
34.19 & 1.40 & 24 \\
37.07 & 1.59 & 16 \\
39.04 & 1.59 & 16 \\
41.40 & 1.58 & 14 \\
43.27 & 1.59 & 14 \\
45.69 & 1.56 & 14 \\
48.54 & 1.57 & 13 \\
51.50 & 1.57 & 13 \\
54.32 & 1.55 & 13 \\
56.92 & 1.59 & 13 \\
60.92 & 1.57 & 13 \\
64.31 & 1.47 & 13 \\
67.88 & 1.47 & 13 \\
\hline \hline
\end{tabular}


TABLE III: SOIL ELECTRICAL RESISTIVITY VALUE, MOISTURE CONTENT AND BULK DENSITY DATA FOR $3 \%$ (45 ML) OF WATER

\begin{tabular}{ccc}
\hline MC $(\%)$ & $\begin{array}{c}\mathrm{P}_{\text {bulk }} \\
\left(\mathrm{Mg} / \mathrm{m}^{3}\right)\end{array}$ & $\rho(\Omega \mathrm{m})$ \\
\hline 8.34 & 1.01 & 7700 \\
10.66 & 1.03 & 3400 \\
13.10 & 1.01 & 3300 \\
16.22 & 0.96 & 2100 \\
18.18 & 0.96 & 1350 \\
21.07 & 0.94 & 850 \\
24.62 & 0.87 & 550 \\
27.24 & 0.85 & 290 \\
31.03 & 0.94 & 110 \\
34.54 & 1.47 & 26 \\
36.84 & 1.65 & 18 \\
32.85 & 1.69 & 16 \\
43.35 & 1.59 & 17 \\
46.07 & 1.56 & 16 \\
49.37 & 1.55 & 15 \\
52.90 & 1.57 & 15 \\
56.96 & 1.56 & 15 \\
61.32 & 1.60 & 14 \\
65.55 & 1.52 & 14 \\
67.16 & 1.50 & 14 \\
69.58 & 1.49 & 14 \\
74.86 & 1.46 & 14 \\
88.69 & 1.45 & 14 \\
93.29 & 1.36 & 14 \\
100.45 & 1.36 & 14 \\
\hline \hline
\end{tabular}

TABLE IV: Soil ELECTRICAL RESistivity VALUe, MoistuRE CONTENT AND BULK DENSITY DATA FOR $4 \%$ (60 ML) OF WATER

\begin{tabular}{ccc}
\hline \hline MC $(\%)$ & $\begin{array}{c}\text { Pbulk } \\
(\mathrm{Mg} / \mathrm{m} 3)\end{array}$ & $\rho(\Omega \mathrm{m})$ \\
\hline 9.13 & 1.02 & 7200 \\
15.77 & 1.00 & 3150 \\
19.27 & 0.97 & 1900 \\
23.47 & 0.93 & 1000 \\
27.75 & 0.83 & 700 \\
31.91 & 0.88 & 170 \\
36.04 & 1.17 & 50 \\
39.52 & 1.60 & 17 \\
43.49 & 1.58 & 16 \\
47.12 & 1.59 & 16 \\
51.52 & 1.56 & 15 \\
55.17 & 1.58 & 14 \\
61.31 & 1.58 & 14 \\
63.26 & 1.57 & 14 \\
67.99 & 1.54 & 14 \\
77.68 & 1.53 & 14 \\
75.66 & 1.46 & 14 \\
83.48 & 1.47 & 14 \\
91.52 & 1.46 & 14 \\
81.48 & 1.37 & 15 \\
110.22 & 1.41 & 15 \\
116.39 & 1.31 & 15 \\
100.73 & 1.33 & 15 \\
75.12 & 1.31 & 16 \\
& 1.31 & 16 \\
\hline \hline
\end{tabular}

\section{ACKNOWLEDGMENT}

First author wish to acknowledge gratefully to supervisors and research members for their tremendous guidance, work and cooperation.

\section{REFERENCES}

[1] C. R. I. Clayton, M. C. Matthews, and N. E. Simons, Site Investigation, 2nd ed. U.K.: Blackwell Science Ltd, 1995, ch. 4.

[2] R. Saad, N. M. Muztaza, and E. T. Mohamad, "The 2D Electrical Resistivity Tomography (ERT) Study for Civil and Geotechnical Engineering Purposes," Electronic Journal of Geotechnical Engineering, vol. 16, pp. 1537-1545, 2011.

[3] Z. Jusoh, "Application of 2-D resistivity imaging and seismic refraction technique in subsurface investigation for civil engineering," M.S. thesis, Sch. Physics, Science Univ., Penang, Malaysia, 2010.
[4] K. A. N. Adiat, M. N. Nawawi, and K. Abdullah, "Assessing the accuracy of GIS-based elementary multi criteria decision analysis as a spatial prediction tool - A case of predicting potential zones of sustainable groundwater resources," Journal of Hydrology, vol. 440-441, pp. 75-89, March 2012.

[5] R. Saad, M. N. M. Nawawi, and E. T. Mohamad, "Groundwater Detection in Alluvium Using 2-D Electrical Resistivity Tomography (ERT)," Electronic Journal of Geotechnical Engineering, vol. 17, pp. 369-376, 2012.

[6] U. Hamzah, A. R. Samsudin, and E. P. Malim, "Groundwater investigation in Kuala Selangor using vertical electrical sounding (VES) surveys," Environmental Geology, vol. 51, pp. 1349-1359, July 2006.

[7] U. Hamzah, R. Yaacup, A. R. Samsudin, and M. S. Ayub, "Electrical imaging of the groundwater aquifer at Banting, Selangor, Malaysia," Environmental Geology, vol. 49, pp. 1156-1162, March 2006.

[8] M. F. T. Baharuddin, S. Taib, R. Hashim, M. H. Z. Abidin, and M. F. Ishak, "Time-lapse resistivity investigation of salinity changes at an ex-promontory land: a case study of Carey Island, Selangor, Malaysia," Environmental Monitoring and Assessment, vol. 180, pp. 345-369, Dec. 2010.

[9] A. R. Samsudin, A. Haryono, U. Hamzah, and A. G. Rafek, "Salinity mapping of coastal groundwater aquifers using hydrogeochemical and geophysical methods: a case study from north Kelantan, Malaysia," Environmental Geology, vol. 55, pp. 1737-1743, Dec. 2007.

[10] A. R. Samsudin, B. E. A Rahim, W. Z. W. Yaacob, U. Hamzah, "Mapping of contamination plumes at municipal solid waste disposal sites using geoelectric imaging technique: Case studies in Malaysia," Journal of Spatial Hydrology, vol. 6, no. 2, 2006.

[11] R. Saad, I. Adli, and A. S. Mohamad, "The Study of Iron Ore Prospect using 2-D Resistivity and Induced Polarization (IP) Method," Electronic Journal of Geotechnical Engineering, vol. 17, pp. 2981-2988, 2012.

[12] R. Saad, M. M. Saidin, N. M. Muztaza, N. A. Ismail, N. E. H. Ismail, "Subsurface Study Using 2-D Resistivity Imaging Method for Meteorite Impact at Bukit Bunuh, Perak," Electronic Journal of Geotechnical Engineering, vol. 16, pp. 1507-1513, 2011.

[13] R. Whitlow, Basic Soil Mechanics, 4th ed. Dorset: Prentice Hall, 2001, ch. 12.

[14] W. M. Telford, L. P. Geldart, and R. E. Sheriff, Applied Geophysics, 2nd ed. Cambridge: Cambridge University Press, 1990, ch. 5.

[15] D. H. Griffiths and R. F. King, Applied Geophysics for Geologist and Engineers The Element of Geophysical Prospecting, Oxford: Pergamon Press, 1981, ch. 2.

[16] Methods of test for Soils for civil engineering purposes-Part 2. Classification tests, British standard 1377-2:1990.

[17] F. I. Siddiqui and S. B. A. S. Osman, "Integrating Geo-Electrical and Geotechnical Data for Soil Characterization," International Journal of Applied Physics and Mathematics, vol. 2, no. 2, pp. 104-106, March 2012.

[18] F. Ozcep, E. Yildirim, O. Tezel, M. Asci, and S. Karabulut, "Correlation between electrical resistivity and soil-water content based artificial intelligent techniques," International Journal of Physical Sciences, vol. 5, no. 1, pp. 47-56, Jan. 2010.

[19] P. Cosenza, E. Marmet, F. Rejiba, Y. J. Cui A. Tabbagh, and Y. Charlery, "Correlations between geotechnical and electrical data: A case study at Garchy in France," Journal of Applied Geophysics, vol. 60, pp. 165-178, Feb. 2006.

[20] V. A. Rinaldi, and G. Cuestas, "Ohmic Conductivity of a Compacted Silty Clay," Journal of Geotechnical and Geoenvironmental Engineering, vol. 128, no. 10, pp. 824-835, Oct. 2002.

[21] O. Tezel and F. Ozcep, "Relationships of electrical resistivity and geotechnical parameters," in Proc. of Conf. on Earth Sciences and Electronics, Istanbul, Turkey, 2003.

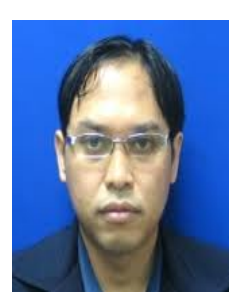

Mohd Hazreek Zainal Abidin is a $\mathrm{PhD}$ student at the Geophysics section, School of Physics, Universiti Sains Malaysia, MALAYSIA. Since 2004 until present, he was associated with Universiti Tun Hussein Onn Malaysia, MALAYSIA (UTHM). He received a Bachelor Degree in Engineering (Civil)(Hons) from Universiti Teknologi Mara, MALAYSIA (2004) and Master Degree in Engineering (Civil-Geotechnics) from Universiti Teknologi Malaysia, Malaysia (2006).

He has experience working as an academician since 2004 at Faculty of Civil and Environmental Engineering, Uthm. Starting as a Uthm's Tutor back to 2004, he upgrade his career as a LECTURER from 2006 until present. 
He has a variety of academic and research experience involving teaching, research, consultancy, publication and management during his services in UTHM. As for teaching experiences, he was involved with various undergraduate subject such as basic geology, engineering geology and rock mechanics, geotechnics, foundation engineering, geotechnics and geology laboratory, integrated design project and already produced two teaching module for engineering geology and slope stabilization respectively. He was actively involved in several research and consultation projects in related to the applied geophysics due to slope forensic study, groundwater exploration, ground stiffness study and mineral exploration using his research grant from UTHM and other collaboration agencies involving private and government sector. Currently, he had publish six journal articles and eighteen conference proceedings related to applied geophysics, geotechnics, engineering geology and rock mechanics and was appointed as a Head Of Engineering Geology And Geophysics Laboratory (2007-2009). His research interests include applied geophysics: resistivity and seismic study, geotechnical engineering, rock mechanics and engineering geology, soil and rock slope, soil and rock testing.

Mr. Mohd Hazreek Bin Zainal Abidin was a member of Board of Engineers Malaysia (BEM), Geological Society of Malaysia and National Tropical Rock Engineering Research Group (NatROCK). He was awarded as an excellent staff from his employer during 2010 UTHM quality day.

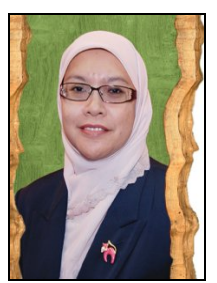

Fauziah Ahmad is a Professor at School of Civil Engineering, Universiti Sains Malaysia, Malaysia (USM). She received a Bachelor Degree and $\mathrm{PhD}$ from University of Strathclyde Glasgow, United Kingdom (1985 and 1989).

She has experience working as an academician since 1998 at School of Civil Engineering, USM. She has a variety of academic and research experience

involving teaching, research, consultancy, publication and management during her services in USM.

Her field of specialization was geotechnical engineering involving ground improvement, slope stability, GIS, foundation engineering, etc.

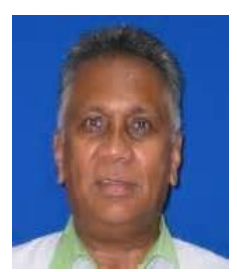

Devapriya Chitral Wijeyesekera is a Professor at Research Center for Soft Soil, Universiti Tun Hussein Onn Malaysia, MALAYSIA and Formerly Professor in Civil Engineering at School of Architecture, Computing and Engineering, University of East London. He received a Bachelor Degree in Civil Engineering at University of Ceylon (1968) and subsequently read for his MSc and $\mathrm{PhD}$ at
Imperial College of Science and Technology (University of London).

He has experience has over 35 years' experience in teaching, research, consultancy and management in Civil Engineering at University of East London and Universiti Tun Hussein Onn Malaysia. He maintains collaborative research links with many UK (Oxford, Cambridge, Imperial College, Nottingham Trent) and overseas (Brunei, Japan, Malaysia, Singapore and Sri Lanka) Universities, Water Utility companies (Thames Water) and field research centers (RECESS in Malaysia). He has published widely and written over sixty publications. His field of specialization was on geotechnical engineering involving problematic soil, ground improvement, slope stability, GIS, foundation engineering, engineering geology and rock mechanics, etc.

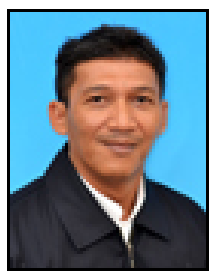

Rosli Saad is a Senior Lecturer at Geophysics Section, School of Physics, Universiti Sains Malaysia, MALAYSIA (USM). He received a Bachelor Degree Master Degree and PhD at USM.

He has experience working as an academician since 1986 at School of Physics, USM. He has a variety of academic and research experience involving teaching, research, consultancy, publication and management during his services in USM. His field of specialization was on geophysical exploration using resistivity, seismic, ground penetrating radar, etc.

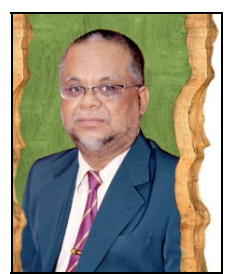

Ahmad Shukri Yahya is an Associate Professor at Geophysics Section, School of Civil Engineering, Universiti Sains Malaysia, Malaysia (USM). He received a Bachelor Science in Mathematics at University of Nottingham, England (1982) and Master Science in Industrial Mathematics from University of Aston, Birmingham England (1983).

He has a variety of academic and research

experience involving teaching, research, consultancy, publication and management during his services in USM. His field of specialization was on data analysis, simulation and operational research. 